\title{
Análise morfométrica do endotélio corneano de coelhos à microscopia eletrônica de varredura
}

\author{
Morphometric analysis of the corneal endothelium of rabbits using scanning electron microscopy

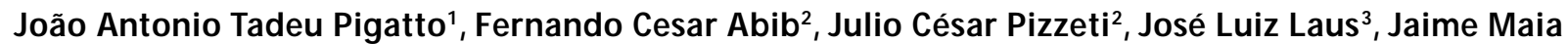 \\ dos Santos ${ }^{3} \&$ Paulo Sergio de Moraes Barros ${ }^{4}$
}

\begin{abstract}
RESUMO
O endotélio, constituído de uma monocamada de células poligonais, constitui-se na estrutura mais posterior da córnea. Objetivou-se examinar a superfície posterior do endotélio corneano e realizar análise morfométrica das células endoteliais da córnea de coelhos valendo-se da microscopia eletrônica de varredura. Avaliaram-se o número de lados, a área celular média, a densidade celular e o coeficiente de variação da área celular. O endotélio corneano de coelhos constitui-se de células poligonais uniformes em tamanho e forma, e com interdigitações das bordas celulares. Vizibilizaram-se microvilosidades na superfície celular. Relativamente à forma celular encontraram-se células na maioria hexagonais (75\%) com células pentagonais (14\%) e heptagonais $(11 \%)$ constituindo o restante do endotélio corneano. A área celular média foi de $174 \pm 32 \mu \mathrm{m}^{2}$ e a densidade celular foi de $5747 \pm 238$ células por milímetro quadrado. O coeficiente de variação foi de 0.21 . Não foram observadas diferenças significativas entre os parâmetros avaliados entre os olhos esquerdo e direito. Este estudo demonstrou que o endotélio corneano de coelhos é semelhante ao descrito em outros vertebrados.
\end{abstract}

Descritores: endotélio corneano, morfometria, microscopia eletrônica de varredura, coelhos.

\section{ABSTRACT}

The endothelium is a single layer of polygonal cells covering the posterior surface of the cornea. The aim of this study was to examine the endothelial surface morphology and to perform morphometric analysis of the corneal endothelial cells of rabbits using scanning electron microscopy. Morphometric analysis with regard to polygonality, mean cell area, cell density and coefficient of variation of mean cell area was performed. The corneal endothelium of rabbits consisted of polygonal cells of uniform size and shape with interdigitations of the cell borders. Microvilli appearead on the cellular surface. Regarding the polygonality of endothelium, the predominant number of cells was hexagonal (75\%) in shape with pentagonal (14\%), and heptagonal (11\%) cells constituting the greater portion of the remaining corneal endothelium. The mean cell area was $174 \pm 32 \mu \mathrm{m}^{2}$ and the cell density was $5747 \pm 238$ cells per milimeters square. The coefficient of variation of cell area was 0.21 . This study demonstrates that the rabbit's corneal endothelium is similar to those described in other vertebrates.

Key words: corneal endothelium, morphometry, scanning electron microscopy, rabbits. 


\section{INTRODUÇÃO}

O endotélio corneano apresenta sua face anterior voltada para a membrana de Descemet, enquanto a posterior limita-se com o humor aquoso [24]. Na maioria das espécies ocorre decréscimo da densidade endotelial e modificações da morfologia celular com o avanço da idade [1,8]. Além da influência da idade o endotélio pode ser alterado por inúmeros fatores incluindo trauma e inflamação intraocular [16,22].

Entre as técnicas utilizadas para avaliar a morfometria endotelial encontram-se os métodos de investigação clínica e os estudos in vitro [6,25]. Clinicamente a microscopia especular tem sido amplamente empregada permitindo, além dos resultados de exames in vivo, o registro fotográfico das células endoteliais $[1,4,5,17]$. Das técnicas in vitro a microscopia eletrônica de varredura tem se mostrado de grande valia para o estudo quanto à toxicidade de drogas intracamerulares, à eficácia de meios de preservação de córneas e em investigações da ultra-estrutura endotelial $[2,3,7,16,18]$. Entre os principais parâmetros endoteliais mensuráveis encontram-se a contagem celular e a variação do tamanho e da forma de suas células [8]. A espécie leporina tem sido amplamente empregada como modelo experimental em pesquisas que avaliaram lesões endoteliais secundárias a procedimentos cirúrgicos e a fármacos intra-oculares $[2,3,10,11,20]$. No entanto, as referências detalhando as condições do endotélio corneano normal dessa espécie limitam-se a avaliações fazendo uso somente da microscopia especular $[9,14,19]$.

Objetivou-se examinar a superfície endotelial posterior e realizar análise morfométrica das células do endotélio corneano de coelhos valendo-se da microscopia eletrônica de varredura.

\section{MATERIAIS E MÉTODOS}

Empregaram-se 15 coelhos, clinicamente sadios, raça Nova Zelândia Branco, machos ou fêmeas, com três meses de idade, provenientes do Departamento de Anatomia da Faculdade de Medicina da Universidade Federal do Paraná. A pesquisa foi conduzida obedecendo-se os critérios recomendados pelo Colégio Brasileiro de Experimentação Animal
(COBEA). Imediatamente após a eutanásia dos animais procedeu-se exame oftálmico a fim de confirmarem as condições de higidez da córnea.

Realizou-se enucleação subconjuntival e as córneas foram obtidas, fixadas em glutaraldeído ${ }^{1}$ a 2,5\% em tampão de cacodilato de sódio $20,1 \mathrm{M} \mathrm{e} \mathrm{pH}$ 7,4 durante 8 horas e seccionadas em tamanhos correspondentes a $1 / 4$ do total da superfície corneana.

O processamento e a análise das amostras foram realizados no Laboratório de Microscopia Eletrônica de Varredura da Faculdade de Ciências Agrárias e Veterinárias - UNESP - Campus de Jaboticabal. As córneas foram lavadas na solução tampão e desidratadas em concentrações ascendentes de álcool etílico $(30,50,70,85,90$ e $100 \%)$, sendo 15 minutos para cada concentração, e três vezes na concentração de $100 \%$. Ato contínuo foram secas em secador de ponto crítico utilizando-se dióxido de carbono líquido. Foram fixadas em porta-espécime, com fita condutiva de cobre e cola de carbono, e metalizadas com uma camada de ouro e paládio de $35 \mathrm{~nm}$ de espessura durante dois minutos. Cada amostra foi examinada em microscópio eletrônico de varredura $^{3}$ operado com $15 \mathrm{Kv}$. Foram feitas cinco eletromicrografias da região central da córnea com aumento de 750 vezes. Ocasionalmente, obtiveram-se imagens com outros aumentos.

Para o estudo morfométrico empregou-se o software para análise morfométrica ${ }^{4}$. Após a digitalização das imagens o número de lados foi determinado e a área celular unitária de 50 células endoteliais de cada amostra aferida. A densidade endotelial, expressa em células $/ \mathrm{mm}^{2}$, foi obtida utilizandose a transformação matemática: Densidade de células endoteliais (células $/ \mathrm{mm}^{2}$ ) = 1000 000/área celular $\left(\mu \mathrm{m}^{2}\right)$. Calculou-se o coeficiente de variação da área celular média. As médias obtidas foram comparadas através do teste de Tukey $(\mathrm{P}<0,05)$.

\section{RESULTADOS}

O endotélio corneano de coelhos caracterizou-se por uma monocamada de células poligonais uniformes em tamanho e forma (Figura 1).

As bordas celulares apresentaram interdigitações e sobre a superfície celular observou-se um número variável de microvilosidades (Figura 2). 


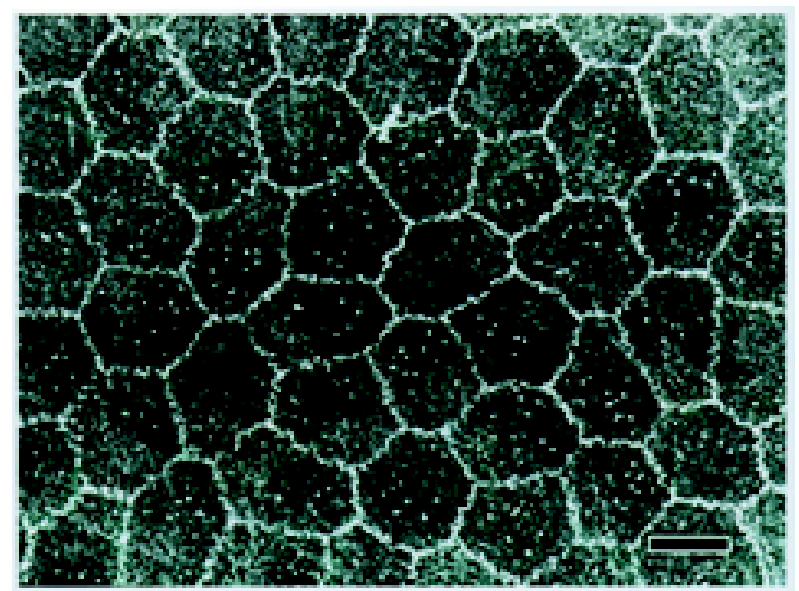

Figura 1. Eletromicrografia de varredura do endotélio corneano de coelho. Notar células poligonais uniformes em tamanho e forma $(1500 \mathrm{X}$. Barra $=10 \mu \mathrm{m})$.

Relativamente à forma celular, encontraramse células hexagonais $(75 \%)$, pentagonais $(14 \%)$ e heptagonais (11\%). A área celular média foi de 174 $\pm 32 \mu \mathrm{m}^{2} \mathrm{e}$ a densidade endotelial de $5747 \pm 238$ células por milímetro quadrado. O grau de polimegatismo foi de 0.21 .

Não foram observadas diferenças significativas entre os parâmetros avaliados entre os olhos esquerdo e direito.

\section{DISCUSSÃO}

Entre os fatores responsáveis pela manutenção da transparência corneana, encontram-se a integridade morfológica e funcional do endotélio [24]. Os estudos valendo-se da microscopia eletrônica de varredura demonstraram que, com exceção das bordas celulares, dos cílios e das microvilosidades, a superfície posterior do endotélio é plana, e que as bordas celulares apresentam interdigitações [13,21].

Neste estudo interdigitações das bordas celulares e microvilosidades foram visibilizadas. Entretanto, cílios que ocasionalmente são encontrados nas células endotelias não foram evidenciados. Investigações prévias informam da fragilidade dos cílios durante o preparo de córneas para estudos à microscopia eletrônica [13]. O preenchimento da câmara anterior com solução de glutaraldeído, antes da remoção da córnea, conforme recomendação de Doughty [10], provavelmente permitiria que essas estruturas fossem preservadas no momento do preparo das córneas.

No estudo morfométrico somente células da região central da córnea foram analisadas. Como em indi-

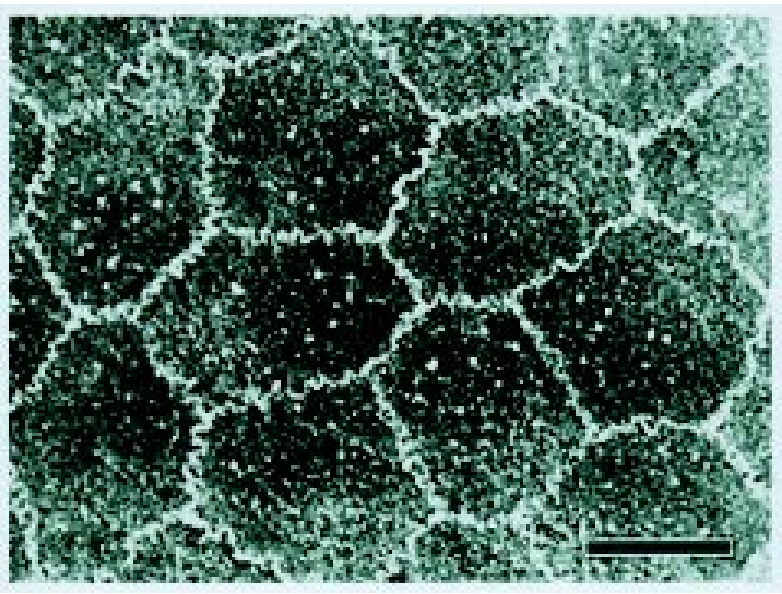

Figura 2. Eletromicrografia de varredura do endotélio corneano de coelho. Notar inderdigitações das bordas celulares e microvilosidades na superfície celular $(2000 \mathrm{X}$. Barra $=10 \mu \mathrm{m})$.

víduos com córnea hígida a distribuição celular é uniforme entre as regiões central e periférica, valendo-se somente do estudo da área corneana central, há como se estimar a contagem celular e a morfologia de todo o contingente celular do endotélio [14,19]. Além disso, estudos prévios demonstraram que a retração celular decorrente do preparo de córneas destinadas à microscopia eletrônica de varredura ocorre uniformemente [23]. Entretanto, em avaliações endoteliais após procedimentos cirúrgicos intracamerulares além da região central, áreas periféricas devem ser examinadas pois nestas situações as perdas endoteliais ocorrem de forma heterogênea [16].

O endotélio corneano é uma monocamada constituída, em sua maioria, por células hexagonais, ocasionalmente pentagonais, mas que podem apresentar quatro, sete ou até oito lados [8]. Observaram-se células poligonais com padrão regular e com predomínio da forma hexagonal, similar ao descrito em outras espécies $[6,17,18]$. Normalmente o porcentual de células hexagonais aproxima-se de $70 \%$ e o seu declino é indicativo de menor reserva funcional [8].

Dentre os métodos utilizados para análise morfométrica do endotélio corneano, destacam-se as microscopias especular e eletrônica de varredura $[1,3,4,8,25]$. O advento do microscópio especular permitiu a análise e o registro fotográfico das células endoteliais $[1,4,5,17,25]$. O fato de ser uma técnica não invasiva e a simplicidade operacional constituem vantagens da microscopia especular [16]. Sua utilização evita ainda com que artefatos provenientes da preparação de córneas para estudo à microscopia eletrônica sejam observados 
$[9,14,15]$. Entretanto o alto custo do microscópio especular e a dificuldade em se obterem imagens em áreas endoteliais que sofreram trauma levam muitas vezes a necessidade de utilização de técnicas alternativas.

Entre as técnicas para estudo in vitro, a microscopia eletrônica de varredura tem sido amplamente utilizada para analisar repercussões de fármacos e procedimentos operatórios intracamerulares e descrever a ultra-estrutura do endotélio corneano em diferentes espécies $[3,6,7,16,18]$.

A espécie leporina é utilizada em pesquisas experimentais que avaliam a repercussão de fármacos ou procedimentos intra-oculares sob o endotélio corneano [9,14,15]. A área celular média do endotélio corneano de coelhos, que geralmente é obtida valendo-se da microscopia especular varia entre 274,6 e $317,4 \mu \mathrm{m}^{2}$ $[9,15,19]$. Com esta mesma técnica os valores da densidade celular os valores variam entre 2268 e 3791 células por milímetro quadrado $[9,15,19]$.

Os resultados deste estudo mostraram valores da área celular variando entre 368 e $675 \mu \mathrm{m}^{2}$. A densidade celular encontrada oscilou entre 5463 e 5755 células por milímetro quadrado. Apesar do seu considerável uso reconhece-se que as etapas do preparo de córneas para estudos à microscopia eletrônica de varredura induzem graus variáveis de retração celular, com diminuição da área celular original e aumento da densidade endotelial $[11,23]$. Neste sentido, não seria possível compararmos diretamente os valores obtidos neste estudo com aqueles da microscopia especular. Além disso, não encontramos investigações que propusessem relações de equivalência entre as duas técnicas. Mesmo com os efeitos do preparo das córneas para estudo à microscopia eletrônica de varredura o coeficiente de variação da área celular en- contrado de 0,21 foi semelhante aos valores publicados valendo-se da microscopia especular [6,25].

No presente estudo não foram evidenciadas diferenças quanto aos parâmetros endoteliais entre um olho e o seu contralateral. As informações da literatura asseguram a inexistência de diferenças significativas quanto aos parâmetros endoteliais obtidos entre um olho e o seu contralateral $[4,14,17,18]$.

A despeito das intercorrências decorrentes da retração tecidual a microscopia eletrônica de varredura permitiu que importantes detalhes da ultra-estrutura endotelial pudessem ser observados e quantificados. A complexidade e os cuidados no preparo de córneas para estudos à microscopia eletrônica de varredura, aliados ao alto custo e à necessidade de treinamento prévio, sem os quais os riscos de comprometimento das amostras seriam eminentes, constituem-se em obstáculos para a sua utilização [3,18]. A realização de treinamento prévio assegurou adequada preparação das amostras sem que artefatos ou outras intercorrências pudessem ser atribuídos à execução da técnica.

\section{CONCLUSÃo}

Mediante os resultados encontrados é possível concluir que o endotélio corneano normal de coelhos é similar ao descrito em outras espécies.

NOTAS INFORMATIVAS

${ }^{1}$ Glutaraldehyde, Electron Microscopy Sciences, Washington, EUA.

${ }^{2}$ Sodium Cacodylate Trihydrate, Electron Microscopy Sciences, Washington, EUA.

${ }^{3}$ Scanning Electron Microscope JEOL-JSM 5410, Maryland, EUA.

${ }^{4}$ Image Tool, University of Texas Health Science Center, San Antonio, Texas, EUA.

\section{REFERÊNCIAS}

1 Abib F.C. \& Barreto Jr. J. 2001. Behavior of corneal endothelial density over a lifetime. Journal of Cataract and Refractive Surgery. 27: 1574-1578.

2 Alp B.N., Elibol O., Sargon M.F., Aslan O.S., Yanyali A., Karabas L., Talu H. \& Caglar Y. 2000. The effect of povidine iodine on the corneal endothelium. Cornea. 19: 546-550.

3 Alves E.A.F. 2001. Efeito da lidocaína a $1 \%$ sem preservativo sobre o endotélio corneano de coelhos: estudo comparativo pelas microscopias especular e eletrônica de varredura. 2001. 129f. Belo Horizonte, MG. Tese (Doutorado em Medicina) Faculdade de Medicina, Universidade Federal de Minas Gerais.

4 Andrew S.E., Ramsey D.T., Hauptamn J.C. \& Brooks D.E. 2000. Density of corneal endothelial cells and corneal thickness in eyes of euthanatized horses. American Journal of Veterinary Research. 162: 479-482.

5 Andrew S.E., Willis A.M. \& Anderson D.E. 2002. Density of corneal endothelial cells, corneal thickness, and corneal diameters in normal eyes of llamas and alpaca. American Journal of Veterinary Research. 63: 326-329. 
6 Colin S.P. \& Collin H.B. 1998. A comparative study of the corneal endothelium in vertebrates. Clinical and Experimental Optometry. 81: 245-254.

7 Collin S.P. \& Collin H.B. 2000. The corneal endothelium in the Blowfish (Torquigener pleurogramma). Cornea. 19: 231-235.

8 Doughty M.J. 1989. Toward a quantitative analysis of corneal endothelial cell morphology: A review of techniques and their application. Optometry \& Vision Science. 66: 626-642.

9 Doughty M.J. 1994. The cornea and corneal endothelium in the aged rabbit. Optometry \& Vision Science. 71: 809-818.

10 Doughty M.J. 1998. Changes in cell surface primary cilia and microvilli concurrent with measurements of fluid flow across the rabbit corneal endothelium ex vivo. Tissue \& Cell. 30: 634-643.

11 Doughty M.J., Bergmanson J.P.G. \& Blocker Y. 1997. Shrinkage and distortion of the rabbit corneal endothelial cell mosaic caused by a high osmolality glutaraldehyde-formaldehyde fixative compared to glutaraldehyde. Tissue \& Cell. 9: 533-547.

12 Gallagher B.C. 1980. Primary cilia of the corneal endothelium. The American Journal of Anatomy. 159: 475-484.

13 Gwin R.M., Lerner I., Warren J.K. \& Gun G. 1982. Decrease in canine corneal endothelial cell density and increase in corneal thickness as function of age. Investigative Ophthalmology \& Vision Science. 22: 267-271.

14 Morita H. 1995. Specular microscopy of corneal endothelial cells in rabbits. Journal of Veterinary Medicine \& Science. 57: 273-277.

15 Peiffer R.L., De Vanzo R.J. \& Cohen K.L. 1981. Specular microscopic observations of clinically normal feline corneal endothelium. American Journal of Veterinary Research. 42: 854-855.

16 Pigatto J.A.T. 2004. Extração extracapsular do cristalino, comparativamente à facoemulsificação, com enfoque nas repercussões endoteliais corneanas em cães (Canis familiaris - Linnaeus, 1758). 112f. São Paulo, SP. Tese (Doutorado em Medicina Veterinária) - Programa de Pós-graduação em Cirurgia da Faculdade de Medicina Veterinária e Zootecnia, Universidade de São Paulo.

17 Pigatto J.A.T., Abib F.C., Laus J.L. \& Freire C.D. 2003. Pleomorphism and polymegathism of normal corneal endothelial cells in dogs. In: Meeting of International Society of Veterinary Ophthalmology (Cambridge, England). p.126.

18 Pigatto J.A.T., Andrade M.C., Laus J.L., Santos J.M., Brooks D.E., Guedes P.M. \& Barros P.S.M. 2004. Morphometric analysis of the corneal endothelium of Yacare Cayman (Caiman yacare) using scanning electron microscopy. Veterinary Ophthalmology. 7: 205-208.

19 Sailstad D.M. \& Peiffer Jr. R.L. 1981. Specular microscopic observations of the corneal endothelium in the normal rabbit. Laboratory Animals. 15: 393-395.

20 Scharf J. \& Nahir A.M. 1991. Endothelial cells of rabbit cornea in different storage conditions. Ophthalmic Research. 23: 98-103.

21 Schutten W.H. \& Van Horn D.L. 1980. Corneal endothelial cell shrinkage after critical point drying. Annals of Ophthalmology. 46: 1165-1167.

22 Tuft S.J. \& Coster D.J. 1990. The corneal endothelium. Eye. 4: 389-424.

23 Virtanen J., Uusitalo H., Palkama A. \& Kaufman H. 1984. The effect of fixation on corneal endothelial cell dimensions and morphology in scanning electron microscopy. Acta Ophthalmologica. 62: 577-585.

24 Waring G.O., Bourne W.M. \& Edelhauser H.F. 1982. The corneal endothelium. Normal and pathologic structure and function. Ophthalmology. 89: 531-590.

25 Yee R.W., Edelhauser H.F. \& Stern M.E. 1987. Specular microscopy of vertebrae corneal endothelium: a comparative study. Experimental Eye Research. 44: 703-714.

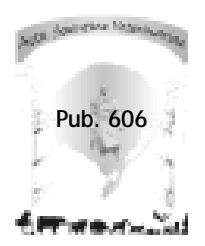

